\title{
Rupture of Sinus of Valsalva with Endocarditis and Aortic Root Abscess
}

\author{
Arif Maqsood $\mathrm{Ali}^{{ }^{*}}$, Gule Raana Waseem², Shazia Arif ${ }^{3}$ and Muhammad Ali $^{2}$ \\ ${ }^{1}$ Department of Pathology and Blood Bank, Rawalpindi Institute of Cardiology, Pakistan \\ ${ }^{2}$ Rawalpindi Institute of Cardiology, Pakistan \\ ${ }^{3}$ Graded Specialist, Community health, AMC, Pakistan
}

\begin{abstract}
Received: 16 October, 2017; Accepted: 21 December, 2017; Published: 28 December, 2017
*Corresponding author: Arif Maqsood Ali, Assistant Professor of Microbiology, Department of Pathology \& Blood Bank, Rawalpindi Institute of Cardiology, Rawalpindi, Punjab, Pakistan, Tel: +923217415605, +92519281111; E-mail: drarifmaqsoodali@hotmail.com
\end{abstract}

\begin{abstract}
A ruptured sinus of Valsalva aneurysm rarely accompanies the aortic valve endocarditis. A 40 year old female presented with low threshold exertional dyspnea and fever. Transthoracic and transesophageal echocardiography showed ruptured sinus of Valsalva aneurysm in right ventricle with multiple vegetations at the aortic root. Initial blood cultures were negative and an empirical antibiotic therapy was started. Patient was operated for surgical repair of sinus of Valsalva aneurysm.
\end{abstract}

An aortic root abscess with rupture of sinus of Valsalva was found at operation. However, postoperatively she developed sepsis and multiorgan failure leading to her death.

Keywords: Aortic Aneurysm; Aortic Rupture; Sinus of Valsalva; Infective Endocarditis; Aortic Abscess; Trans-Esophageal Echocardiography;

\section{Introduction}

A Sinus of Valsalva Aneurysm (SOVA) is an enlargement of the aortic root area between the aortic valve annulus and the sinotubular ridge. In a normal heart, both the left and right sinus contain their respective coronary artery ostia, whereas the posterior sinus is a non coronary sinus [1].

SOVA is a congenital or acquired cardiac defect which is found in roughly $0.09 \%$ of the general population [2]. Less commonly, it is associated with endocarditis, atherosclerosis, trauma, syphilis, or aortic dissection. Its incidence is five times higher in Asian countries with male/female ratio as 4:1 [2, 3].

The anatomic setting of a SOVA usually predicts the clinical outcome of aneurysm rupture. Rupture of the right and non coronary sinuses typically results in communication between the aorta and the right ventricular outflow tract or the aorta and the right atrium. Symptoms include substernal chest pain, abdominal pain and mild to severe dyspnea. In many cases, patients may experience symptoms of acute heart failure, cardiac tamponade, hemodynamic instability and even cardiac death [4].
Diagnosis is confirmed by transesophageal echocardiography or catheterization [5].

Endocarditis (IE) can complicate rupture of sinus of Valsalva \& vice versa $[6,7,8]$. Aortic root abscess is the most severe sequela of infective endocarditis and its surgical management is a complicated procedure because of the high risk of morbidity and death [9]. SOVA with aortic root abscess has rarely been reported.

\section{Case Report}

A 40 year old normotensive and normoglycemic women presented in emergency department of a tertiary care cardiac hospital in Rawalpindi, Pakistan on May 23rd 2017. She complained of shortness of breath, fever and pain in right hypochondrium for last 15 days. Her past history was insignificant. On clinical examination, she was anemic, febrile and looked lethargic. She had a temperature of $101^{\circ} \mathrm{F}$, pulse rate of $101 /$ minute and respiratory rate of $30 /$ minute. Her jugular venous pressure was raised with prominent right sided facial veins. A loud continuous sawing murmur was heard throughout the first and second heart sounds. ECG showed sinus tachycardia. Arterial blood gas analysis revealed oxygen desaturation. Laboratory investigations showed Haemoglobin (Hb) 7.1g/dl, White Cell Count (WBCs) count of $16.1 \times 10^{9} / 1$ with normal hepatic and renal profile. Mantoux test, Antinucleur Antibody and VDRL were negative. X-rays chest showed markedly dilated right vena caval shadow. Initial blood culture did not yield any growth. Transthoracic and Transesophageal echocardiography showed aneurysmal tissue of aortic root with small multiple vegetations $2-3 \mathrm{~mm}$. Intravenous antibiotics for culture negative endocarditis were started which included intravenous inj. Ceftriaxone $1 \mathrm{~g}$ every 12 hourly, inj Vacomycin 500mg every 12 hourly and inj. Levofloxacin $500 \mathrm{mg}$ once daily. At operation, there was rupture of SOVA with small aortic root abscess at its base. The aortic root abscess was excised and necrotic tissue was removed. Reconstruction of aortic root was done with bovine pericardial patch. 
Postoperatively, the patient condition deteriorated and she could not be weaned off from ventilator. Her repeat complete picture showed $\mathrm{Hb} 10 \mathrm{~g} / \mathrm{dl}$, WBCs count 18.9 X 10/L\& platelet count $23 \times 10^{12} /$ ul. Complement Reactive Protien (CRP) was $114 \mathrm{~g} / \mathrm{dl}$. Her liver \& renal biochemical profile showed Alanine Aminotransferase (ALT) $259 \mathrm{U} / \mathrm{l}$, Alkaline phosphatase (ALP) $278 \mathrm{U} / \mathrm{l}$, Urea $190 \mathrm{mmol} / \mathrm{l}$, Creatinine $2.3 \mathrm{mg} / \mathrm{dl}$. D dimers were more than $200 \mathrm{ng} / \mathrm{ml}$. Blood culture yielded growth of Escherichia coli sensitive to Piperacillin/Tazobactem and resistant to all other antibiotics. Piperacillin/Tazobactem $3.75 \mathrm{~g}$ iv 8 hourly was started. However, she went into cardiopulmonary arrest. She was resuscitated but could not be revived (Figure 1, 2, 3, 4, 5).

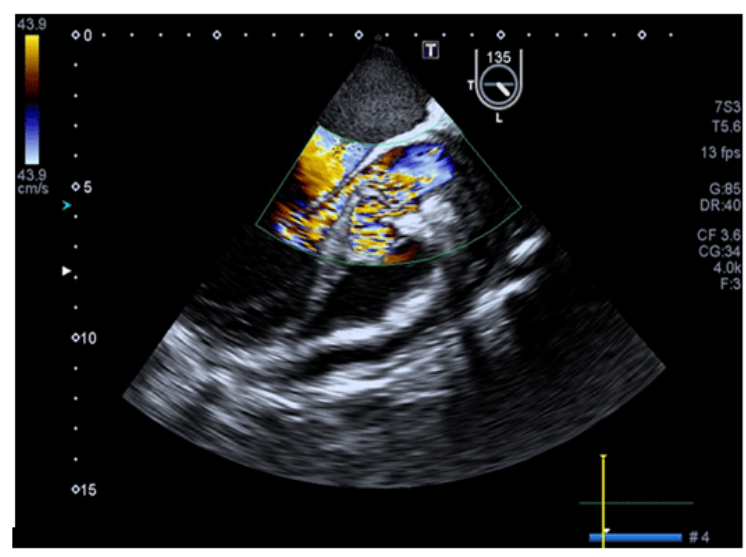

Figure 1: Transoesophageal echocardiography at mid esophageal position at 135 degree left ventricle long axis view showing the colour M mode cut section at aortic sinuses level shows an abnormal aliasing at $43.9 \mathrm{~cm} / \mathrm{sec}$ aliasing velocity, below the right sinus of Valsalva into RV.

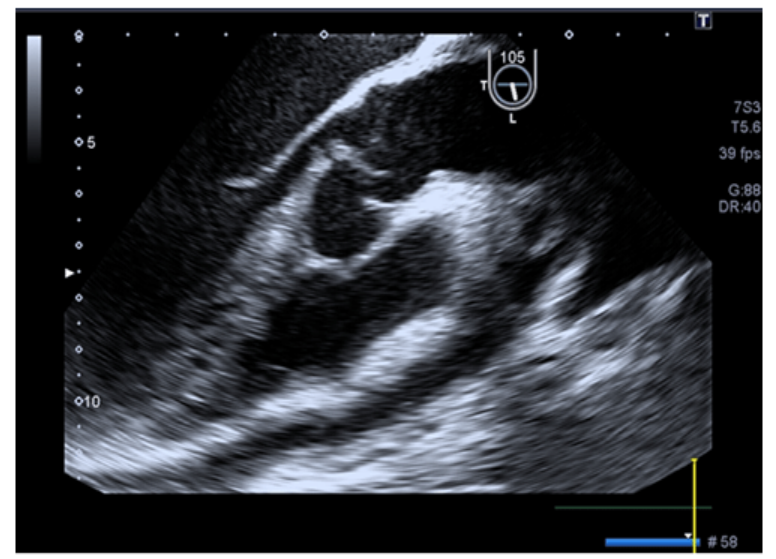

Figure 2: Transoesophageal echocardiography at mid esophageal position at 135 degree left ventricle long axis view showing the 2D colour imaging modality with clear flow from right sinus of Valsalva in to RV.

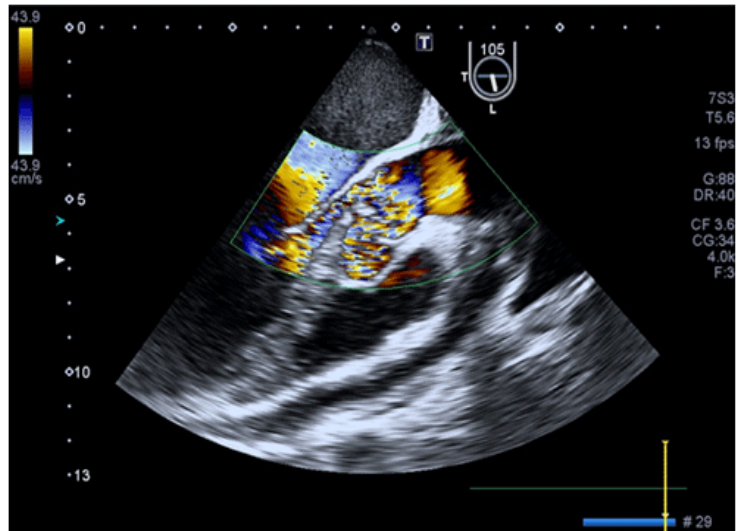

Figure 3: Transoesophageal echocardiography at mid esophageal position at 105 degree left ventricle long axis view showing 2D image of clear rupture right sinus of Valsalva.

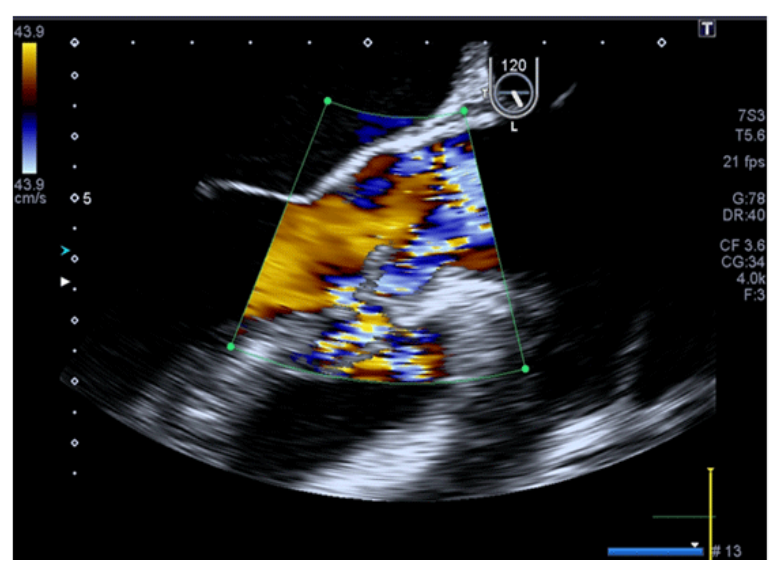

Figure 4: Transoesophageal echocardiography at mid esophageal position at 105 degree left ventricle long axis view. The 2D n colour Doppler image shows clear flow from rupture right sinus of valsalv into RV and small mobile vegetation attached at right coronary cusp on the aortic side measuring $6 \mathrm{~mm}$.

Figure 5: Transoesophageal echocardiography at mid esophageal position at 105 degree left ventricle long axis view. The 2D n colour Doppler image shows clear flow from rupture right sinus of valsalv into RV and small mobile vegetation attached at right coronary cusp on the aortic side measuring $6 \mathrm{~mm}$. 


\section{Discussion}

Sinus of Valsalva Aneurysm (SOVA) is a rare disorder. It is usually congenital, but other origins have been described. It may be asymptomatic or it may present as angina or with symptoms of valvular insufficiency or outflow obstruction [5]. It can become complicated with rupture or infection $[6-8,10]$.

Rupture of a SOVA occurs most commonly at the right ventricle (60\%), right atrium (29\%), followed by the left atrium (6\%), left ventricle $(4 \%)$ and at pericardium $(1 \%)[11,12]$. Incidence of ruptured SOVA is $0.46 \%-3.5 \%$ and $0.14 \%-0.23 \%$ in Eastern and Western countries respectively. Its incidence is five times higher in Asian population with male/female ratio as 4:1 [3]. The unruptured SOVA often remains undiagnosed but may manifest with symptoms of right ventricular outflow obstruction [13].

Once ruptured, SOVA often leads to hemodynamic instability. Transesophageal echocardiography or catheterization is required to confirm the diagnosis [5].

Infective endocarditis has been reported in patients with ruptured SOVA. Both bacterial endocarditis leading to rupture of sinus of Valsalva and sinus of Valsalva rupture leading to infective endocarditis has been cited in literature $[6,7]$. However, SOVA with aortic root abscess has rarely been reported. In our patient, there was ruptured sinus of Valsalva aneurysm and a small aortic root abscess with small multiple vegetations $2-3 \mathrm{~mm}$ in size. The prognosis of infective endocarditis depends upon whether the infected valve is native or prosthetic $[14,15,16]$. The type $\&$ virulence of the microorganism and resistance of the host are important in determining the fate of IE; it's complications like paravalvular abscess, cardiac fistulas and severe destruction of the native aortic valve. A mechanical valve is often infected in its sewing ring and the infection also extends into surrounding structures [9]. The microbiology of the IE also depends on the nature of valve i.e. native or prosthetic. Native-valve endocarditis causing perianular abscess involves aortic valve more often than mitral valve [17].

An uncontrolled aortic root abscess is often complicated by a burrowing abscess, a cardiac fistula or a rupture into a cardiac chamber, a pseudoaneurysm, or an arrhythmia that can lead to hemodynamic instability. Early and extensive surgical resection of aortic root abscess followed by its reconstruction can be life saving as antibiotics alone are usually ineffective to stop the destruction of cardiac tissue by the abscess [9].

In our study, the presence of sepsis, multiorgan failure \& coagulopathy lead to the fatal outcome of the case. A large, multicenter, international study showed that $22 \%$ of patients with aortic valve IE had perianular abscess which was more frequent in prosthetic valves than with native valves (40\% vs $19 \%$ ) [18].

SOVA complicated with endocarditis or sepsis has 4-5 times greater risk of perioperative death [13]. The operative mortality rate for the surgical treatment of aortic root abscess varies from $3.9 \%$ to $25 \%[18,19]$. Early intervention for IE with extended sequelae is known to have better outcome. Surgeons therefore opt for an early operation if life-threatening sequelae do not develop [20]. Most urgent surgical series have high mortality rates, ranging from $55 \%$ to $77 \%[14,21]$.

\section{Conclusion}

Although rupture of sinus of Valsalva is a rare condition in young to middle aged patients. It can be life threatening condition due to hemodynamic instability and can lead to acute heart failure or sudden death. Bacterial endocarditis and aortic root abscess can complete SOVA which should be confirmed by transesophageal echocardiography or cardiac catheterization. Urgent Surgical repair and appropriate antibiotic therapy should be considered to decrease morbidity\& mortality due to the disease and its complications.

\section{References}

1. Bricker AO, Avutu B, Mohammed TL, Eric EW, Imran SS, Paul RJ, et al. Valsalva sinus aneurysms: findings at CT and MR imaging. Radiographics. 2010;30(1):99-110.

2. Weinreich M, Yu PJ, Trost B. Sinus of valsalva aneurysms: review of the literature and an update on management. Clinical Cardiology. 2015;38(3):185-189. doi: 10.1002/clc.22359

3. Chu SH, Hung CR, How SS, Chang H, SS Wang, Tsai CH, et al. Ruptured aneurysms of the sinus of valsalva in oriental patients. J Thorac Cardiovasc Surg. 1990;99(2):288-298.

4. Feldman DN, Roman MJ. Aneurysms of the sinuses of valsalva. Cardiology. 2006;106:73-81.

5. Miranda D, Peter AA, Osorio J, Ferreira AC. Ruptured aneurysm of the noncoronary sinus of Valsalva. Tex Heart Inst J. 2005;32(4):586-588.

6. Vereckei A, Vándor L, Halász J, Karádi I, Lengyel M. Infective endocarditis resulting in rupture of sinus of Valsalva with a rupture site communicating with both the right atrium and right ventricle. J Am Soc Echocardiogr 2004;17(9):995-997.

7. Encarnacion CO, Loranger AM, Bharat kumar AG, Almassi GH. Bacterial Endocarditis caused by Lactobacillus acidophilus Leading to Rupture of Sinus of Valsalva Aneurysm. Tex Heart Inst J. 2016;43(2):161164. doi: 10.14503/THIJ-15-5121

8. Ikeda A, Nakajima T, Konishi T, Kanji Matsuzaki, Akinori Sugano, Yuko Fumikura, et al. Infective endocarditis of an aorto-right atrial fistula caused by asymptomatic rupture of a sinus of Valsalva aneurysm: a case report. Surg Case Rep. 2016;2:43. doi: 10.1186/s40792-0160171-4

9. Kirali K, Sarikaya S, Ozen Y, Hakan Sacli MD, Eylul Basaran, Ozge Altas Yerlikhan, et al. Surgery for Aortic Root Abscess: A 15-Year Experience. Texas Heart Institute Journal. 2016; 43(1):20-28. doi:10.14503/ THIJ-14-4747.

10. Patra KP, Vanchiere JA, Bocchini JA jr, Amy C Wu, Robert D Jackson MD, et al. Endocarditic with rupture sinus of Valsalva aneurysm caused by non vaccine streptococcal pneumonia serotype 21.Tex Heart Institute J. $2012 ; 39(2): 277-280$. 
11. Vautrin E, Barone-Rochette G, Philippe J. Rupture of right sinus of Valsalva into right atrium:Ultrasound, magnetic resonance, angiography and surgical imaging. Arch Cardiovasc Dis. 2008;101(78):501-502. doi: 10.1016/j.acvd.2008.06.003

12. Missault L, Callens B, Taeymans Y. Echocardiography of sinus of Valsalva aneurysm with rupture into the right atrium. Int J Cardiol. 1995;47(3):269-272.

13. Kutiyal AS, Daga MK. Ruptured Sinus of Valsalva with Infective Endocarditis Complicated with Post-Infectious Acute Glomerulonephritis: A Rare Case Presentation. Journal of clinical and diagnostic research. 2016;10(10):OD14- OD15.

14. David TE, Regesta T, Gavra G, Armstrong S, Maganti MD. Surgical treatment of paravalvular abscess: long-term results. EurJ Cardiothorac Surg 2007; 31(1):43-48. doi.org/10.1016/j.ejcts.2006.10.036

15. Yankah AC, Pasic M, Klose H, Siniawski H, Weng Y, Hetzer R. Homograft reconstruction of the aortic root for endocarditis with periannular abscess: a 17-year study. Eur J Cardiothorac Surg. 2005;28(1):69-75.

16. Leontyev S, Borger MA, Modi P, Lehmann S, Seeburger J, Doenst T, Mohr FW. Surgical management of aortic root abscess: a 13-year experience in 172 patients with 100\% follow up. J Thorac Cardiovasc Surg. 2012;143(2):332-337. Doi: 10.1016/j.jtcvs.2010.10.064
17. Kirali K, Guler M, Yakut N, Mansuroglu D, Omeroglu SN, Daglar B, et al. Combined medical and surgical treatment for active native valve infective endocarditis: ten-year experience. Turk Kardiyol Dern Ars 2001; 29(9):543-548.

18. Anguera I, Miro JM, Cabell CH, Abrutyn E, Fowler VG Jr, Hoen B, et al. Clinical characteristics and outcome of aortic endocarditis with periannular abscess in the International Collaboration on Endocarditis Merged Database. Am J Cardiol. 2005; 96(7):976-981.

19. Murdoch DR, Corey GR, Hoen B, Miro JM, Fowler VG Jr, Bayer AS, et al. Clinical presentation, etiology, and outcome of infective endocarditis in the 21st century: the International Collaboration on EndocarditisProspective Cohort Study. Arch Intern Med 2009;169(5):463-473. doi: 10.1001/archinternmed.2008.603

20. Knosalla C, Weng Y, Yankah AC, Siniawski H, Hofmeister J, Hammerschmidt R, et al. Surgical treatment of active infective aortic valve endocarditis with associated periannular abscess--11 year results. Eur Heart J. 2000;21(6):490-497.

21. Kirali K, Mansuroglu D, Omeroglu SN, Erentug V, Mataraci I, Ipek G, et al. Five-year experience in aortic root replacement with the flanged composite graft. Ann Thorac Surg 2002;73 (4):1130-1137. doi. org/10.1016/S0003-4975(01)03604-9 